\title{
Feminine heart puzzle in 2015
}

\section{Nurgül Keser ${ }^{1}$}

1) University of Sakarya Faculty of Medicine Department of Cardiology, Prof. Dr., Sakarya, Turkey

\begin{abstract}
In order to decrease the cardiovascular morbidity and mortality special attention should be given to the feminine heart. The first step is to evaluate the major differences in the pathophysiology,symptom onset and clinical outcomes of ischemic heart disease between the genders. Next is to find the best imaging modality that will lead to appropriate treatment.
\end{abstract}

Keywords: Heart disease, coronary artery, female 
Heart disease has been stated to be number one killer in women ${ }^{[1]}$ and in 2015 nothing much seems to have changed. It is still the leading killer of women at all ages affecting more women under the ages of 55 years than breast cancer. ${ }^{[2-5]}$

In order to solve this global problem, special attention should be given to gender differences in the etiology, pathophysiology,clinical presentation, prognosis and treatment of ischemic heart disease(IHD) which has been accepted as a more inclusive term to define the pathology in women. ${ }^{[6]}$

\section{Clinical presentation}

The onset of clinical manifestations of coronary artery disease (CAD) in women has been stated to lag behind men by about 10 years. ${ }^{[1]}$ Following menopause the symptoms become more manifest in women. However instead of typical symptoms, atypical semptoms defined as dyspnea and fatigue may be more prominent in women. ${ }^{[7]}$ Moreover in almost $60 \%$ of women with IHD the initial presentation can be acute myocardial infarction(AMI) or sudden cardiac death ${ }^{[3,4,8-11]}$ and up to $50 \%$ of women presenting with an AMI may not report any prior chest pain symptoms. ${ }^{[2,12]}$

This gender difference in clinical presentation carries utmost importance as it may lead to underdiagnosis of IHD in women.

Moreover,even with the clinical diagnosis of angina and traditional risk factors in women there may not be any evidence of CAD at angiography which was first demonstrated by The Coronary Artery Surgery Study (CASS). ${ }^{[7,13,14]}$

Almost $50 \%$ of women with chest pain suggestive of angina pectoris will have normal or insignificant CAD as compared to $17 \%$ of men and $20 \%$ of these women will still have evidence for myocardial ischemia. ${ }^{[15,16]}$

In such cases coronary microvascular dysfunction involving endothelial and nonendothelial pathways ${ }^{[7,17]}$ can be identified as reported by Reis et al. ${ }^{[18]}$

However ischemia in the setting of vascular dysfunction is not so innocent ${ }^{[8]}$ and coronary endothelial dysfunction is reported to be associated with adverse cardiovascular outcomes regardless of CAD severity in the WISE study. ${ }^{[7,19]}$

The underlying difference in pathophysiology including smaller arterial size, more prominent positive remodeling and greater role of the microvasculature as demonstrated by various noninvasive imaging modalities has been claimed to carry a greater prognostic weight in women. ${ }^{[8,20-27]}$

\section{Risk factors}

As stated before, the CASS study was one of the first landmark studies evaluating the cardiac risk factors in women which showed that the use of traditional risk factor assessment was limited in the prediction of CAD in wome. ${ }^{[7,13,14]}$

The WISE study further revealed that the CV events were independently predicted by coronary vascular endothelial function independent of risk factors and extent of CAD. ${ }^{[15,19]}$

This study also showed prominent gender differences in the impact of $\mathrm{CV}$ risk factors such as not obesity but metabolic syndrome was reported to be a better predictor for the underlying severity of CAD and eventfree survival in women. ${ }^{[15,28,29]}$

Moreover waist circumference has been reported to be a stronger risk factor in women ${ }^{[30]}$ and DASI was reported to be strongly correlated with the occurrence of CAD and adverse events. ${ }^{[31]}$

Bairey Merz CN et al. ${ }^{[32]}$ added new insights to risk factor analysis in women and showed that disruption of ovulatory cycling resulting in hypoestrogenemia in premenopausal women appeared to be associated with increased risk of obstructive CAD which claims that hypoestrogenemia might be the underlying reason for obstructive CAD during the postmenopausal years.

Clear differences also exist regarding the impact of lipid parameters such as Manolio et al. ${ }^{[2,33]}$ reported that HDL cholesterol inversely predicted CAD in younger women and men as well as older ( $>65$ years) women; whereas the relative risks for IHD in women and men as related to total and LDL-cholesterol were found to be similar. ${ }^{[2-4,10]}$ 
As for the triglyceride levels a meta-analysis of 17 studies revealed that hypertriglyceridemia increased the CAD relative risk by $32 \%$ in men and $76 \%$ in women ${ }^{[2,34]}$ and diabetes was also reported to be a stronger risk factor for IHD in women. ${ }^{[2,35]}$

Smoking also deserves special attention in women. As it is complicated by hormonal variables, it has a larger detrimental impact in female hearts and especially in young women smoking is the most important risk factor for sudden cardiac death. ${ }^{[36]} \mathrm{A}$ recent meta-analysis demonstrated a $25 \%$ higher relative risk of heart disease in women smokers compared to men. ${ }^{[37]}$

Specific conditions during pregnancy also need emphasis ${ }^{[35]}$ such as preeclampsia doubles the risk for subsequent $\mathrm{IHD}^{[38]}$ and gestational diabetes increases the risk of development of diabetes and thereby IHD. ${ }^{[39]}$

\section{Prognosis}

As mentioned before $50 \%$ of women referred for the evaluation of suspected myocardial ischemia were found to have no obstructive CAD and the prognosis of future adverse cardiac events was reported to be intermediate for these women. ${ }^{[7]}$

After an acute coronary syndrome(ACS) women and especially younger women with less obstructive CAD will also have a poorer prognosis. ${ }^{[35,40,41]}$

It should also be remembered that although the total number of sudden cardiac deaths is higher in men $^{[42]}, 52 \%$ of women are more likely to die of a cardiac arrest before hospital arrival as compared to $42 \%$ for men. ${ }^{[2,4,42,43]}$

Sex differences in cardiac catheterization and revascularization use and timing which are associated with poorer outcomes in women after an $\mathrm{ACS}^{[35,44-46]}$ cause a dilemma in treating the feminine heart.

Although stent usage is similar in women and men $^{[19,47]}$ they tend to be treated less often with platelet glycoprotein IIb/IIIa receptor antagonists, possibly due to the increased incidence of bleeding which also may limit the effectiveness of the therapy.

Coronary artery Bypass Surgery(CABG) is also troublesome in women.Following $\mathrm{CABG}$ the operative mortality is $4.0 \%$ for women and $3.2 \%$ for men ${ }^{[48]}$, in part due to excessive rates of congestive heart failure. ${ }^{[8,48-51]}$

In addition, women have a higher incidence of bleeding complications ${ }^{[1,19]}$ and a more difficult recovery after $\mathrm{CABG}^{[8,52]}$ which may prolong the duration of hospital stay.

\section{Diagnostic tests}

Due to pathophysiological differences in IHD traditional tests for diagnosis that focus on identifying obstructive CAD work suboptimal in women. ${ }^{[8]}$

Thus a need for an alternative strategy that would rely upon the estimation of the "culprit patient" or prognosis instead of culprit" obstructive coronary lesions has been proposed in wome. ${ }^{[8]}$

In order to choose the best noninvasive imaging modality the American Heart Association (AHA) has proposed to include the pretest risk stratification as low, intermediate and high risk before diagnostic testing referra ${ }^{[53]}$ which added a valuable insight for diagnosis.

We also agree with Lerman et al. ${ }^{[7]}$ who emphasize strongly that nonobstructive coronary angiograms in women should not be ignored and till new imaging modalities that will clearly diagnose ischemia due to vascular dysfunction are utilised, careful attention should be paid to the clear evidences of ischemia such as a positive troponin or an abnormal stress perfusion test in the absence of coronary artery obstruction.

\section{Treatment}

The necessity of earlier and agressive primary prevention in women has been clearly reported. ${ }^{[1]}$ Prudent treatment directed at improving endothelial function, atherosclerosis and established risk factors in women including lipid-lowering, angiotensin-converting enzyme inhibitors and aspirin is well established. ${ }^{[7]}$

However there is still a necessity for the FDA to monitor inclusion of proportional amount of women in all stages of drug research and as offered by Wenger et al. ${ }^{[1]}$ 
further evaluation of the possible sex-based differences in drug metabolism is required before choosing the optimal management strategy for the female heart.

Till the feminine heart puzzle is completely solved there is a compelling need to drive sustained attention to the female heart and remind the physicians to be more more aware of the basic differences between the 2 genders.

\section{References}

1. Nanette K. Wenger. You've Come a Long Way, Baby: Cardiovascular Health and Disease in Women Problems and Prospects. Circulation 2004;109:558-560

2. Leslee J. Shaw, C. Noel Bairey Merz, Carl J. Pepine et al. Insights From the NHLBI-Sponsored Women's Ischemia Syndrome Evaluation (WISE) Study. Part I: Gender Differences in Traditional and Novel Risk Factors, Symptom Evaluation, and Gender-Optimized Diagnostic Strategies. J Am Coll Cardiol 2006;47:4S-20

3. American Heart Association. Heart Disease and Stroke Statistics: 2004 Update. Available at: http://americanheart.org/downloadable/ heart/10 72969766940HSStats2004Update.pdf. Accessed January 15, 2004

4. Make Every Mother and Child Count. Available at: www.cdc.gov/ od/ spotlight/nwhw/whlth05.htm. Accessed November 23, 2005

5. Bell DM, Nappi J. Myocardial infarction in women: a critical appraisal of gender differences in outcomes. Pharmacotherapy 2000;20:1034-44

6. Shaw LJ, Bugiardini R, Merz CN. Women and ischemic heart disease: evolving knowledge. J Am Coll Cardiol. 2009;54(17): 1561-75

7. Amir Lerman, George Sopko Women and Cardiovascular Heart Disease: Clinical Implications From the Women's Ischemia Syndrome Evaluation (WISE) Study Are We Smarter? J Am Coll Cardiol 2006; $47: 59$ S- 62 S

8. C. Noel Bairey Merz, Leslee J. Shaw, Steven E. Reis, Insights From the NHLBI-Sponsored Women's Ischemia Syndrome Evaluation (WISE) Study Part II: Gender Differences in Presentation, Diagnosis, and Outcome With Regard to Gender-Based Pathophysiology of Atherosclerosis and Macrovascular and Microvascular Coronary Disease J Am Coll Cardiol 2006;47:21S-9S

9. Mosca L, Appel LJ, Benjamin EJ, et al. American Heart Association evidence-based guidelines for cardiovascular disease prevention Circulation. 2004 Feb 10;109(5):672-93

10. Lerner DJ, Kannel WB. Patterns of coronary heart disease morbidity and mortality in the sexes: a 26-year follow-up of the Framingham population. Am Heart J 1986;111:383-90

11. Smith SC, Jr., Blair SN, Bonow RO, et al. AHA/ACC guidelines for preventing heart attack and death in patients with atherosclerotic cardiovascular disease: 2001 update: a statement for healthcare profession- als from the American Heart Association and the American College of Cardiology. Circulation 2001;104:1577-79.

12. McSweeney JC, Cody M, O’Sullivan P, Elberson K, Moser DK, Garvin BJ. Women's early warning symptoms of acute myocardial infarction. Circulation 2003;108:2619-23

13. Vlietstra RE, Frye RL, Kronmal RA, Sim DA, Tristani FE, Killip $\mathrm{T}$ 3rd. Risk factors and angiographic coronary artery disease: a report from the Coronary Artery Surgery Study (CASS). Circulation 1980;62:254-61

14. Weiner DA, Ryan TJ, McCabe CH, et al. Exercise stress testing. Correlations among history of angina, ST-segment response and prevalence of coronary-artery disease in the Coronary Artery Surgery Study (CASS). N Engl J Med 1979;301:230 -5

15. Arshed A. Quyyumi Women and Ischemic Heart Disease Pathophysiologic Implications From the Women's Ischemia Syndrome Evaluation (WISE) Study and Future Research Steps, J Am Coll Cardiol 2006;47: $66 \mathrm{~S}-71 \mathrm{~S}$

16. Bairey Merz CN, Kelsey SF, Pepine CJ, et al. The Women's Ischemia Syndrome Evaluation (WISE) study: protocol design, methodology and feasibility report. J Am Coll Cardiol 1999;33:1453-61

17. Sun H, Mohri M, Shimokawa H, Usui M, Urakami L, Takeshita A. Coronary microvascular spasm causes myocardial ischemia in patients with vasospastic angina. Journal of the American College of Cardiology. 2002; 39:847-51

18. Reis SE, Holubkov R, Conrad Smith AJ, et al. Coronary microvascular dysfunction is highly prevalent in women with chest pain in the absence of coronary artery disease: results from the NHLBI WISE study. Am Heart J 2001;141:735- 41

19. von Mering GO, Arant $\mathrm{CB}$, Wessel TR, et al. Abnormal coronary vasomotion as a prognostic indicator of cardiovascular events in women: results from the National Heart, Lung, and Blood Institute- Sponsored Women's Ischemia Syndrome Evaluation (WISE). Circulation 2004;109:722-5

20. Raggi P, Shaw LJ, Berman DS, Callister TQ. Gender-based differences in the prognostic value of coronary calcium. J Women Health 2004;13:273- 83 
21. Hubbard LD, Brothers RJ, King WN, et al. Methods for evaluation of retinal microvascular abnormalities associated with hypertension/ sclerosis in the Atherosclerosis Risk In Communities (ARIC) study. Ophthalmology 1999;106:2269-80

22. Johnson BD, Shaw LJ, Buchtal S, et al. Myocardial ischemia in symptomatic women in the absence of obstructive coronary disease - prognosis and cost: results from the NIH-NHLBI-sponsored Women's Ischemia Syndrome Evaluation (WISE). Circulation 2004;109:2993-9

23. Pepine CJ, Balaban RS, Bonow RO, et al. Women's Ischemic Syndrome Evaluation: current status and future research directions: report of the National Heart, Lung and Blood Institute workshop: October 2-4, 2002: section 1: diagnosis of stable ischemia and ischemic heart disease. Circulation 2004;109:e44-6

24. Newman AB, Naydeck BL, Sutton-Tyrrell K, Feldman A, Edmundowicz D, Kuller LH. Coronary artery calcification in older adults to age 99: prevalence and risk factors. Circulation 2001;104:2679-84

25. Hoff JA, Chomka EV, Krainik AJ, Daviglus M, Rich S, Kondos GT. Age and gender distributions of coronary artery calcium detected by electron beam tomography in 35,246 adults. Am J Cardiol 2001;87: 1335-9

26. Wong ND, Kouwabunpat D, Vo AN, et al. Coronary calcium and atherosclerosis by ultrafast computed tomography in asymptomatic men and women: relation to age and risk factors. Am Heart J 1994;127:422-30

27. Chambless LE, Folsom AR, Clegg LX, et al. Carotid wall thickness is predictive of incident clinical stroke: the Atherosclerosis Risk In Communities (ARIC) study. Am J Epidemiol 2000;151:478-87

28. Kip KE, Marroquin OC, Kelley DE, et al. Clinical importance of obesity versus the metabolic syndrome in cardiovascular risk in women: a report from the Women's Ischemia Syndrome Evaluation (WISE) study. Circulation 2004;109:706 -13

29. Marroquin OC, Kip KE, Kelley DE, et al. Metabolic syndrome modifies the cardiovascular risk associated with angiographic coronary artery disease in women: a report from the Women's Ischemia Syndrome Evaluation. Circulation 2004;109:714-21

30. Ford ES, Dietz WH. Prevalence of the metabolic syndrome among US adults: findings from the third National Health and Nutrition Examination Survey. JAMA 2002;287:356 -9

31. Wessel TR, Arant CB, Olson MB, et al. Relationship of physical fitness vs body mass index with coronary artery disease and cardiovascular events in women. JAMA 2004;292:1179-87

32. Bairey Merz CN, Johnson BD, Sharaf BL, et al. Hypoestrogenemia of hypothalamic origin and coronary artery disease in premenopausal women: a report from the NHLBI-sponsored WISE study. J Am Coll Cardiol 2003;41:413-9

33. Manolio TA, Pearson TA, Wenger NK, Barrett-Connor E, Payne GH, Harlan WR. Cholesterol and heart disease in older persons and women. Review of an NHLBI workshop. Ann Epidemiol 1992;2: 161-76

34. Hokanson JE, Austin MA. Plasma triglyceride level is a risk factor for cardiovascular disease independent of high-density lipoprotein level: a meta-analysis of population-based prospective studies. J Cardiovasc Risk 1996; 3:213-9

35. Gulati M, Shaw LJ, Bairey Merz N. Myocardial ischemia in women-Lessons from the NHLBI WISE study. Clin Cardiol 2012 MArch;35(3):141-148
36. Bolego C, Poli A, Paoletti R. Smoking and gender. Cardiovasc Res.2002;53(3):568-76

37. Huxley RR, Woodward M. Cigarette smoking as a risk factor for coronary heart disease in women compared with men: a systematic review and meta-analysis of prospective cohort studies. Lancet. 2011;378(9799):1297-305.

38. Bellamy L, Casas JP, Hingorani AD, Williams DJ. Pre-eclampsia and risk of cardiovascular disease and cancer in later life: systematic review and meta-analysis. BMJ 2007; 335:974

39. Ratner RE. Prevention of type 2 diabetes in women with previous gestational diabetes. Diabetes Care. 2007; 30(Suppl 2):S242-5

40. Vaccarino V, Parsons L, Every NR, Barron HV, Krumholz HM. Sexbased differences in early mortality after myocardial infarction.National Registry of Myocardial Infarction 2 participants. N Engl J Med 1999; 341:217-25

41. Ford ES, Capewell S. Coronary heart disease mortality among young adults in the U.S. from 1980 through 2002: concealed leveling of mortality rates. Journal of the American College of Cardiology. 2007; 50:2128-32

42. Murphy SL. Death: final data for 1998. Natl Vital Stat Rep 2000;48:1105

43. Lampert R, McPherson CA, Clancy JF, Caulin-Glaser TL, Rosenfeld LE, Batsford WP. Gender differences in ventricular arrhythmia recurrence in patients with coronary artery disease and implantable cardioverter-defibrillators. J Am Coll Cardiol 2004;43:2293-9

44. Jneid H, Fonarow GC, Cannon CP, et al. Sex differences in medical care and early death after acute myocardial infarction. Circulation. 2008; 118:2803-10]

45. Blomkalns AL, Chen AY, Hochman JS, et al. Gender disparities in the diagnosis and treatment of non-ST-segment elevation acute coronary syndromes: large-scale observations from the CRUSADE (Can Rapid Risk Stratification of Unstable Angina Patients Suppress Adverse Outcomes With Early Implementation of the American College of Cardiology/American Heart Association Guidelines) National Quality Improvement Initiative. Journal of the American College of Cardiology. 2005; 45:832-7

46. Lansky AJ. Outcomes of percutaneous and surgical revascularization in women.Progress in cardiovascular diseases.2004;46:305-19

47. Jacobs AK, Johnston JM, Haviland A, et al. Improved outcomes for women undergoing contemporary percutaneous coronary intervention: a report from the National Heart, Lung, and Blood Institute Dynamic Registry. J Am Coll Cardiol. 2002;39:1606-1614

48. Hartz RS, Rao AV, Plomondon ME, Grover FL, Shroyer AL. Effects of race, with or without gender, on operative mortality after coronary artery bypass grafting: a study using the Society of Thoracic Surgeons national database. Ann Thorac Surg 2001;71:51220

49. Hochman JS, Tamis JE, Thompson TD, Weaver WD, White HD, Van de Werf F, et al. Sex, clinical presentation, and outcome in patients with acute coronary syndromes. Global use of strategies to open occluded coronary arteries in acute coronary syndromes IIb investigators. N Engl J Med. 1999;341(4):226-32 
50. Drazner MH, Rame JE, Marino EK, et al. Increased left ventricular mass is a risk factor for the development of a depressed left ventricular ejection fraction within five years: the Cardiovascular Health study. $\mathrm{J}$ Am Coll Cardiol 2004;43:2207-15

51. Ferguson TB, Jr., Hammill BG, Peterson ED, DeLong ER, Grover FL, for the STS National Database Committee. A decade of change - risk profiles and outcomes for isolated coronary artery bypass grafting procedures, 1990-1999: a report from the STS National Database Committee and the Duke Clinical Research Institute. Society of Thoracic
Surgeons. Ann Thorac Surg 2002;73:480-90

52. Vaccarino V, Lin ZQ, Kasl SV, et al. Gender differences in recovery after coronary artery bypass surgery. J Am Coll Cardiol 2003;41:307-14

53. Mieres JH, Gulati M, Bairey Merz N. et al. Role of Noninvasive Testing in the Clinical Evaluation of Women With Suspected Ischemic Heart Disease.A Consensus Statement From the American Heart Association. Circulation 2014;22;130:350-7986.

Received: 23/11/2014

Accepted: 17/01/2015

Published: 15/03/2015

Disclosure and conflicts of interest:

Conflicts of interest were not reported.

Corresponding author:

Prof. Dr. Nurgül Keser

Mail: nkeser@sakarya.edu.tr 